\title{
On the study of train-track dynamic interactions caused by rail welds on discrete supported rails
}

Nekane Correa, Ernesto G. Vadillo, Javier Santamaria and Josu Gómez

Department of Mechanical Engineering, University of the Basque Country UPV/EHU. Alameda Urquijo s.n., 48013 Bilbao, Spain.

NOTICE: this is the author's version of a work that was accepted for publication in Wear. Changes resulting from the publishing process, such as editing, corrections, structural formatting, and other quality control mechanisms may not be reflected in this document. Changes may have been made to this work since it was submitted for publication.

A definitive version was subsequently published in WEAR, VOL. 314, ISSUES 1-2, pp. 291-298, 2014 doi: 10.1016/j.wear.2013.11.044

The final version can be obtained online from:

http://dx.doi.org/10.1016/j.wear.2013.11.044

Please cite this paper as: Correa, N., Vadillo, E.G., Santamaria, J., Gómez, J. On the study of train-track dynamic interactions caused by rail welds on discrete supported rails. Wear, Vol. 314, pp. 291-298. 2014

(C) 2016. This manuscript version is made available under the CC-BY-NC-ND 4.0 license http://creativecommons.org/licenses/by-nc-nd/4.0/ 


\title{
ON THE STUDY OF TRAIN-TRACK DYNAMIC INTERACTIONS
}

\section{CAUSED BY RAIL WELDS ON DISCRETE SUPPORTED RAILS}

\author{
Nekane Correa, Ernesto G. Vadillo*, Javier Santamaria and Josu Gómez \\ Department of Mechanical Engineering, University of the Basque Country UPV/EHU, \\ Escuela Técnica Superior de Ingeniería, Alda Urquijo s/n, 48013 Bilbao, Spain \\ * ernesto.garciavadillo@ehu.es
}

\begin{abstract}
The paper studies the influence of rail weld dip on wheel-rail contact dynamics, with particular reference to freight trains where it is important to increase the operating speed and also the load transported. This has produced a very precise model, albeit simple and cost-effective, which has enabled train-track dynamic interactions over rail welds to be studied to make it possible to quantify the influence on dynamic forces and displacements of the welding geometry; of the position of the weld relative to the sleeper; of the vehicle's speed; and of the axle load and wheelset unsprung mass. It is a vertical model on the spatial domain and is drawn up in a simple fashion from vertical track receptances. For the type of track and vehicle used, the results obtained enable the quantification of increases in wheel-rail contact forces due to the new speed and load conditions.
\end{abstract}

Keywords: rail welds; wheel-rail contact; contact forces; track dynamics; freight trains; speed and tonnage increase

\section{INTRODUCTION}

Rail welds, as the one shown in Fig. 1, can have a major influence on the dynamic behaviour of the entire vehicle-track system, leading in certain cases to substantial impacts, wear, noise, and also the rapid deterioration of vehicle and track components.

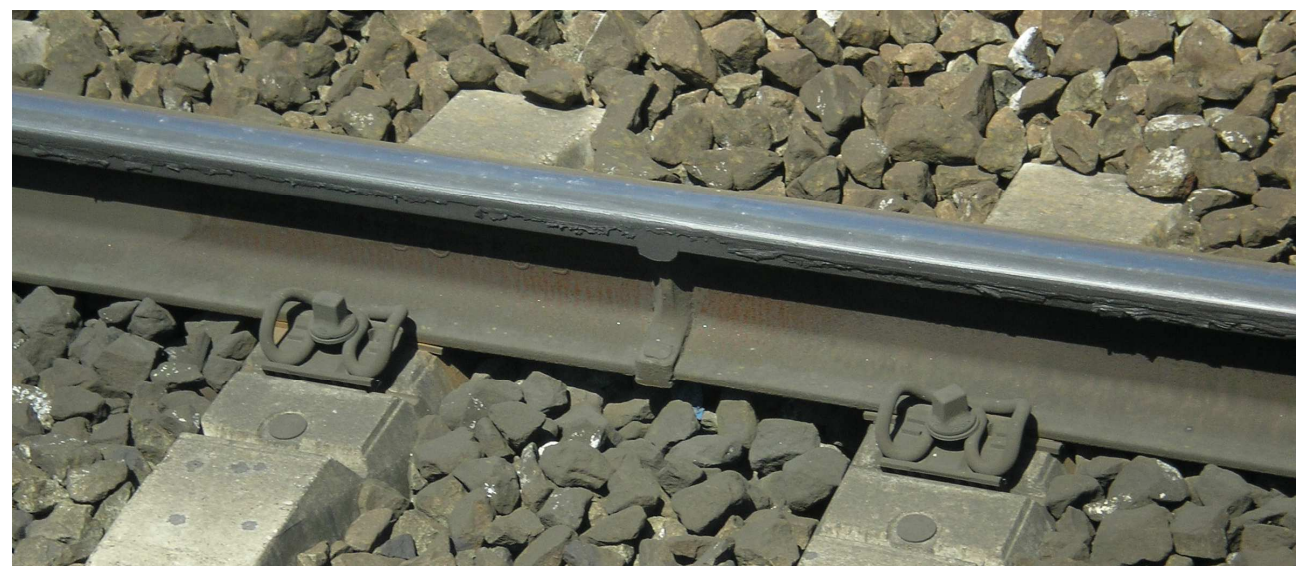

Fig. 1. A typical rail weld in a ballasted track.

There is also a major concern to increase the load of freight transport by rail, in order to remove as many trucks as 
possible from the road system and transfer haulage to the railways. In order to provide more profitable and attractive freight transport for customers, it is necessary to explore higher operating speeds and greater axle loads.

Different track models have been proposed in recent years to study vehicle-track dynamic interaction [1-15]. Some of them have been used to cover vehicle-track interaction at rail welds $[2-4,8,11,12,16]$. Some of these studies were based on three-dimensional finite element models, with a very thorough meshing. On the other hand, this paper adapts and uses a very accurate model, although plain and computing effective for the type and large number of calculations needed. This has made possible to simulate wheel-rail interaction over rail welds and to quantify the influence on dynamic forces and displacements of several factors as: welding geometry; position of the weld relative to the sleeper, axle load and wheelset unsprung mass.

The model used in the paper has already been validated, and a thorough description may be found in [17]. This model has been adapted to undertake the study presented in this paper. The model is a vertical one on the spatial domain and is drawn up in a simple fashion from vertical track receptances. These receptances may be measured experimentally or calculated numerically. In this paper receptances have been calculated using RACING [18] a full track model in the frequency domain already developed by the authors, which takes account of all track components and also deformation of the rail section and propagation of bending, elongation and torsional waves along an infinite track [18]. Receptances are obtained along the rail surface at $4 \mathrm{~cm}$ intervals. During a second stage, a transformation between frequency domain and time domains is secured by applying a modified rational fraction polynomial (RFP) method. This transformation leads to an equivalent track model with very few degrees of freedom, and thus with minimum time consumption for integration, but with an excellent match to the original model over a sufficiently broad range of frequencies which is $0-2000 \mathrm{~Hz}$. Wheel-rail interaction is modelled using a non-linear Hertzian spring. In this paper a single wheelset has been considered moving over the weld in each simulation.

The model takes into consideration the parametric excitation caused by the wheel moving over the sleepers, since this is a moving wheel model and not a moving irregularity model. As the rail vehicle runs along a discretely supported track, the track receptance below the wheel is changing with the position of the contact patch within a sleeper bay. In consequence, it is necessary to calculate track receptances at the different rail sections along the sleeper bay, and to adjust them using the RFP. The track periodicity is introduced into the model by repeating periodically the coefficients of the system of equations (with a spatial period equal to the sleeper bay distance) in every bay travelled by the wheel. It is assumed, therefore, that all the track spans are identical. The difficulty of studying a track with discrete support lies in the extreme variability of the track receptance along a span. With the track dynamic behaviour previously fitted using this method, the dynamic forces and displacements of wheel and rail when the wheelset moves over the irregularity of the weld may be computed with ease.

This study entailed more than 1600 simulations of the forces produced by contact between wheel and rail when the train moves over a rail weld, whereas using other spatial domain models would require excessively long calculation times. Using the method developed for this study, however, the time required to simulate each instance of travel over a weld is a matter of seconds.

The paper draws conclusions concerning the influence of a number of factors - characteristics of the rail vehicle and the depth of the weld irregularity - on the dynamic response of the system. 


\section{METHOD DEVELOPED}

The method is based on joint utilisation of the RFP method [19] and optimisation methods using multiobjective genetic algorithms, in order to obtain a system of equations in the spatial domain the behaviour of which is the same as that of a system described by its receptances. The method is comprehensively explained in [17].

The RFP method was already applied to track studies in $[5,6]$ for continuous and discretely supported track, respectively, although without the advantages and accuracy achieved by using genetic algorithms to carry out the receptance fitting.

The RFP method consists of obtaining in the s-plane (Laplace plane) transfer functions the receptances of which are those given by initial data (track receptances, in this case), which define the behaviour of the system for a given frequency range. These $G(s)$ transfer functions are expressed as polynomial quotients (Eq. (1)), the coefficients of which are calculated by solving the problem of minimising Eq. (2). This corresponds to minimisation of the quadratic error between the original receptance and the receptance fitted during optimisation within the frequency range in which the fitting is being performed, which in this case has been up to $2000 \mathrm{~Hz}$. In Eq. (1), $Y(s)$ is the Laplace transform of the displacement function of the point of the rail in contact with the wheel, $F(s)$ is the Laplace transform of the contact force, and $A(s)$ and $B(s)$ the denominator and numerator of the transfer function. The degrees of the numerator and denominator polynomials $m$ and $n$ of the transfer functions arising from Eq. (1) match the number of zeros and poles of these transfer functions, respectively.

$G(s)=\frac{Y(s)}{F(s)}=\frac{B(s)}{A(s)}=\frac{b_{1} s^{m}+b_{2} s^{m-1}+\ldots+b_{m-1} s+b_{m}}{s^{n}+a_{1} s^{n-1}+a_{2} s^{n-2}+\ldots+a_{n-1} s+a_{n}}$

In Eq. (2), wt is a weight vector for error at the various frequencies at which the fitting is being performed, $\mathbf{h}$ is the track receptance which is being fitted and $\omega$ is the vector of angular frequencies, length $p$.

$\min _{a, b} \sum_{k=1}^{p} \mathbf{w t}(k)\left|\mathbf{h}(k)-\frac{B(\boldsymbol{\omega}(k))}{A(\boldsymbol{\omega}(k))}\right|^{2}$

The transfer function must be calculated on different sections of the track span, usually at constant intervals. When this has been done, the associated system of differential equations is obtained via the inverse Laplace transform of the transfer function. The result of this operation is an ordinary differential equation of an order equal to the order of the denominator polynomial of the transfer function, which can be transformed into a first-order system of differential equations, describing the dynamic behaviour of the track. The coefficients of this system of differential equations are variable in space, since the track receptances vary depending on the section of track span over which the wheelset is travelling.

The weight vectors wt (2) for error at each receptance frequency are extremely important in terms of quality of the receptance fit. The method developed included multiobjective genetic algorithm optimisation for the purposes of calculating the best weight vector to use in the fitting processes. Two objective functions are used. The first is the fit error function, in such a way that any weight vectors producing less error in the fit lead to lower values in the objective function. The second objective function is the function of the order of magnitude of the coefficients. This objective function is important in terms of integration of the equations in the spatial domain, since if the orders of magnitude of the coefficients of the transfer functions on adjacent sections are substantially similar, this makes the integration process much easier.

This system of differential equations was integrated along with the equations for the wheelset, which in this case was taken as a mass (unsprung mass) over which there is a static force corresponding to the weight of the sprung mass. 
Interaction between the wheel and the rail is produced through non-linear Hertzian contact, and hence the Hertzian constant was taken as $c_{H}=93.7 \mathrm{GN} / \mathrm{m}^{3 / 2}$ [6]. This is shown in Fig. 2.

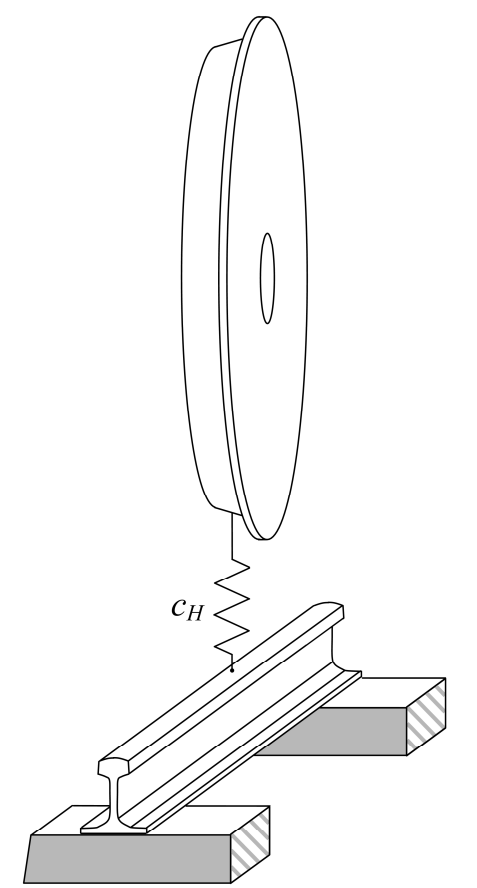

Fig. 2. Non-linear Hertzian wheel-rail contact.

\section{APPLICATION OF THE METHOD DEVELOPED TO THE TRACK}

This section shows the fitting of a ballasted track. This particular track is the one described by Wu and Thompson in [6], with receptances depicted in module and phase in Fig. 3. Table 1 shows the main parameters of this track [17]. The receptances were obtained using the RACING mathematical tool [18], which takes account of all track components, and deformation of the transversal section of the rail and propagation of bending, elongation and torsional waves along an infinite track. As may be observed, there is a substantial amount of variation among track receptances, especially at frequencies in close proximity to the first pinned-pinned mode. This is due to discrete support of the track which, at the frequency of the first pinned-pinned mode, induces a resonance at the track midspan, whereas sections over the sleeper produce anti-resonance in receptances. It may be observed that receptances of sections located between midspan and the sleeper show a resonance and an anti-resonance in close proximity. This major variability of receptances on the various sections of the span makes the fit of receptances through RFP much more complicated than in the case of a track with continuous support.

Table 1: Track parameters [17]

\begin{tabular}{ll}
\hline \hline Pad stiffness $(\mathrm{kN} / \mathrm{mm})$ & 348.6 \\
Pad damping (-) & 0.29 \\
Ballast stiffness $(\mathrm{kN} / \mathrm{mm})$ & 50 \\
Ballast damping (-) & 1 \\
Sleeper mass $(\mathrm{kg})$ & 324 \\
Sleeper spacing $(\mathrm{m})$ & 0.6 \\
Rail & $60 \mathrm{E} 1$ \\
\hline \hline
\end{tabular}


Using this method the vertical track receptances corresponding to 15 positions, separated apart $4 \mathrm{~cm}$ along the span, have been calculated and fitted. Fig. 4 is a dimensional diagram showing such positions.
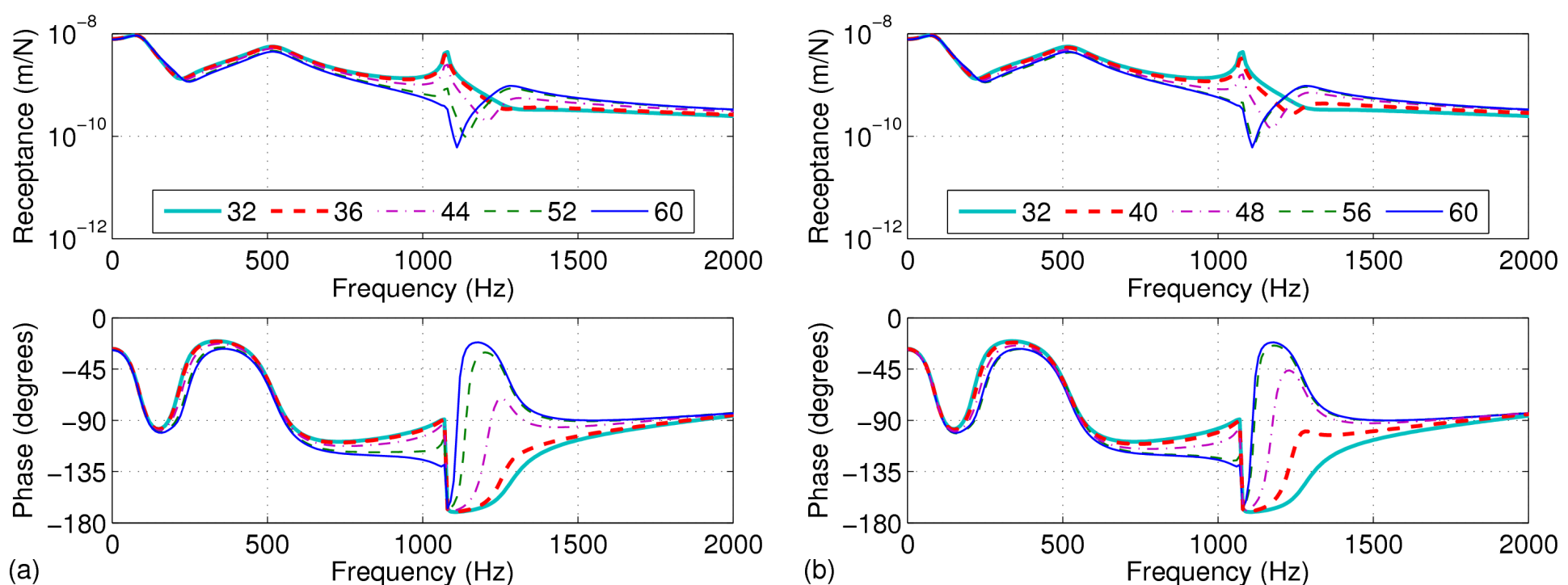

Fig. 3. Vertical receptances of the track in module (upper) and phase (lower) along the span: (a) at 32, 36, 44, 52 and 60 cm; (b) at 32, 40, 48, 56 and $60 \mathrm{~cm}$.

As an example, Figs. 5a and 5b show the receptance fittings over the sleeper and at millimetre 320 produced using the method developed. The fit is more complicated at low frequencies close to zero, even though it remains of good quality. Another frequency at which greater discrepancies may arise between the fit and the original receptance is the first anti-resonance, although it is true that the error incurred at this frequency is not actually so large, since the graph's log scale tends to exaggerate the discrepancies for low receptance values.

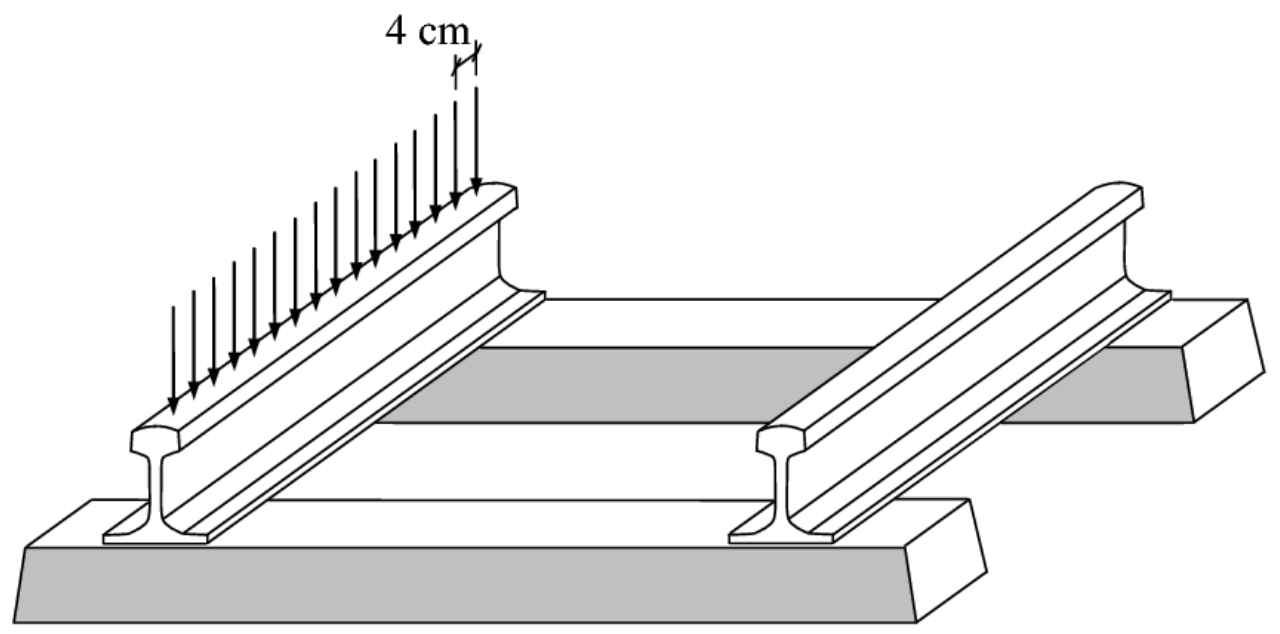

Fig. 4. Distances along the span at which track receptances have been calculated and fitted. 

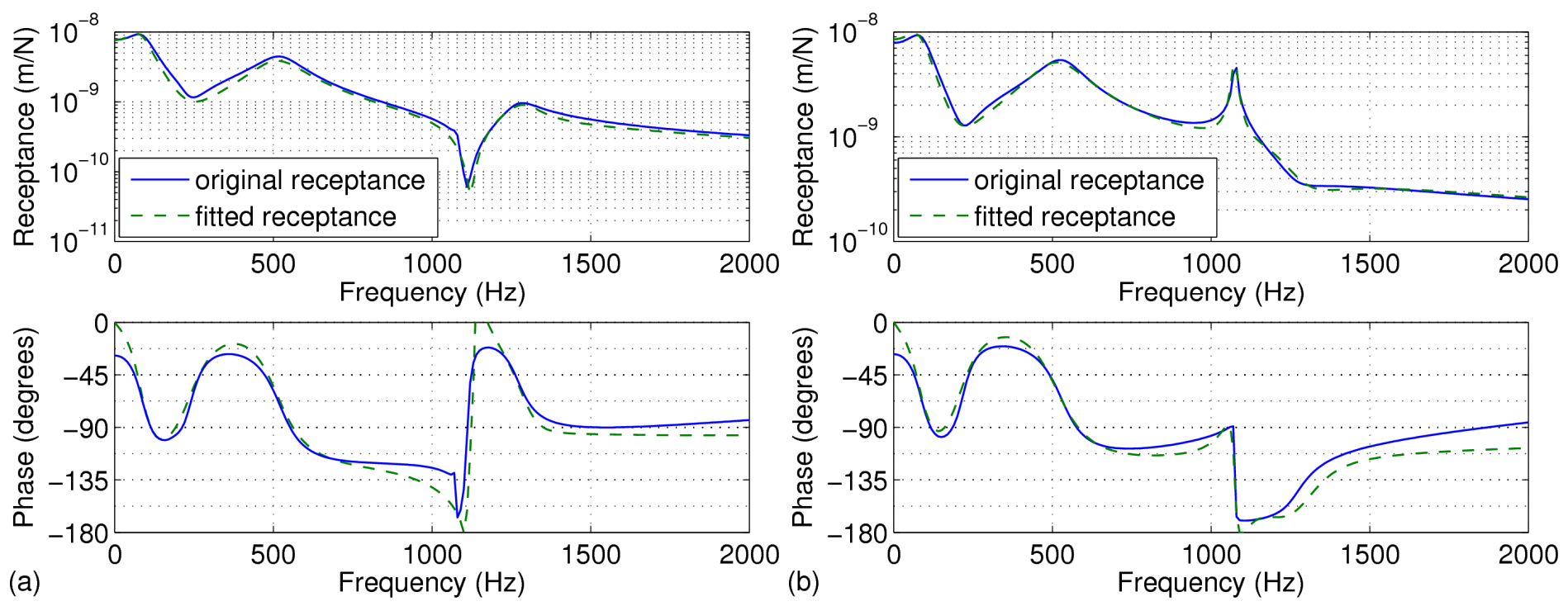

Fig. 5. Receptance fittings: (a) for the section over the sleeper, (b) on the section at millimetre 320 of the span.

\section{VARIATION IN CONTACT FORCES DEPENDING ON THE POSITION OF THE WELD AND ITS AMPLITUDE}

This section sets out the results of integrations of a wheelset moving over a track with a weld dip. The shape of the weld used in the calculations is shown in Fig. 6, obtained from [4]. In this section the wheelset unsprung mass is 1200 $\mathrm{kg}$ and the axle load is 20 tonnes.

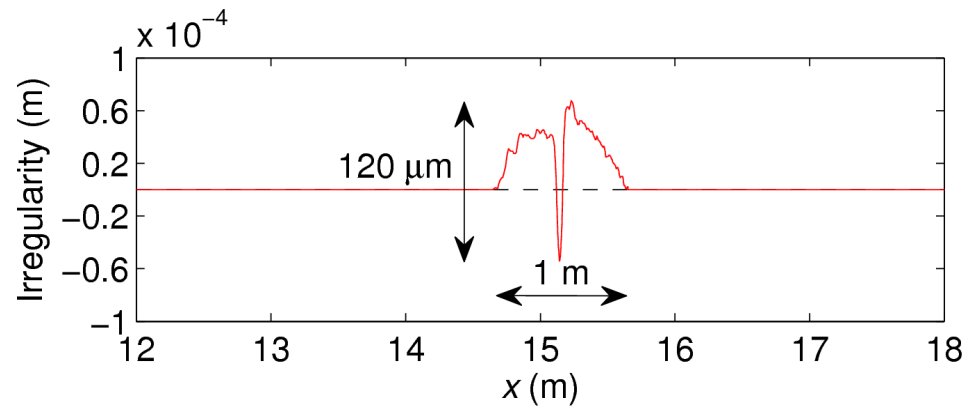

Fig. 6. Shape of the weld dip [4].

In Fig. 7, the horizontal axis represents the distance $d$ from the middle point of the weld to a certain reference sleeper $(d=0)$. For each of these distances the vertical axis represents the maximum force due to the wheel travel over the weld. Each of these values of maximum force in this figure has been obtained simulating the wheel-rail interaction over the weld with a train speed of $120 \mathrm{~km} / \mathrm{h}$. In Fig. 8a, as an example, the wheel-rail contact force is represented against the distance $x$ travelled along the track. The track is represented schematically superimposed on this figure and on all the subsequent figures in which the distance travelled $x$ is represented. Fig. 8a corresponds to the case in which the weld is centred at $40 \mathrm{~cm}(\mathrm{~d}=0,4 \mathrm{~m})$ from the first sleeper. The maximum force resulting in this case appears in Figs. 7 and 8 a marked as 'A' with a circle. Fig. $8 \mathrm{~b}$ shows the force values in the absence of welding. The effect of running over a sleeper can be observed, manifest in the force with a periodicity of $60 \mathrm{~cm}$.

Positions $d=0, d=0.6 \mathrm{~m}$ and $d=1.2 \mathrm{~m}$ in Fig. 7 represent welds centred over the sleeper. For this type of track, four force peaks can be seen between $d=0 \mathrm{~m}$ and $d=0.6 \mathrm{~m}$. These peaks are the result of a combined effect of the wheel 
moving over a rail with discrete supports and the effect of the wheel passing over a rail weld. It may be observed that the peak amplitude changes considerably as the distance $d$ from welding to sleeper changes, and hence the importance of consideration of discrete support in this study.

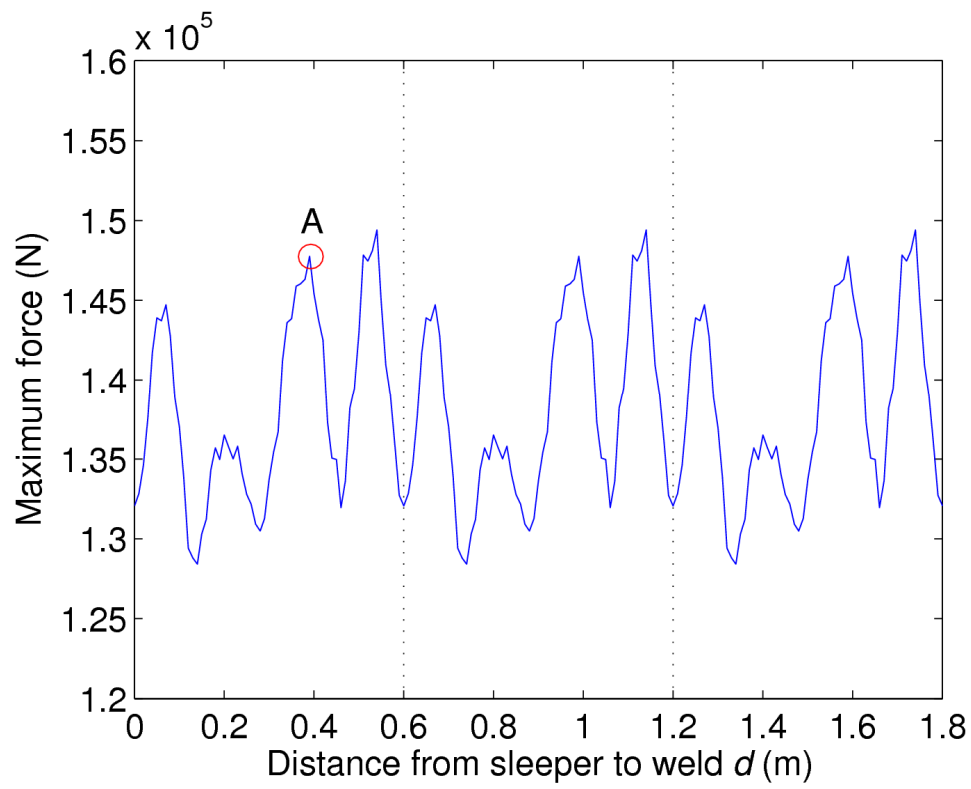

Fig. 7. Maximum values of forces during travel over a weld centred on different sections of the span.

Fig. 9 shows the increase in maximum contact force due to the weld for different positions. In this figure, again, the horizontal axis represents the distance $d$ from the middle point of the weld to a certain reference sleeper $(d=0)$. In the vertical axis the maximum contact force increase due to the wheel moving over the weld is calculated identifying the maximum after subtracting the forces of Fig. $8 \mathrm{~b}$ to the forces of Fig. 8a. It has therefore been deducted the component of the force due to the discrete rail supports. This calculation is repeated for each distance $d$.
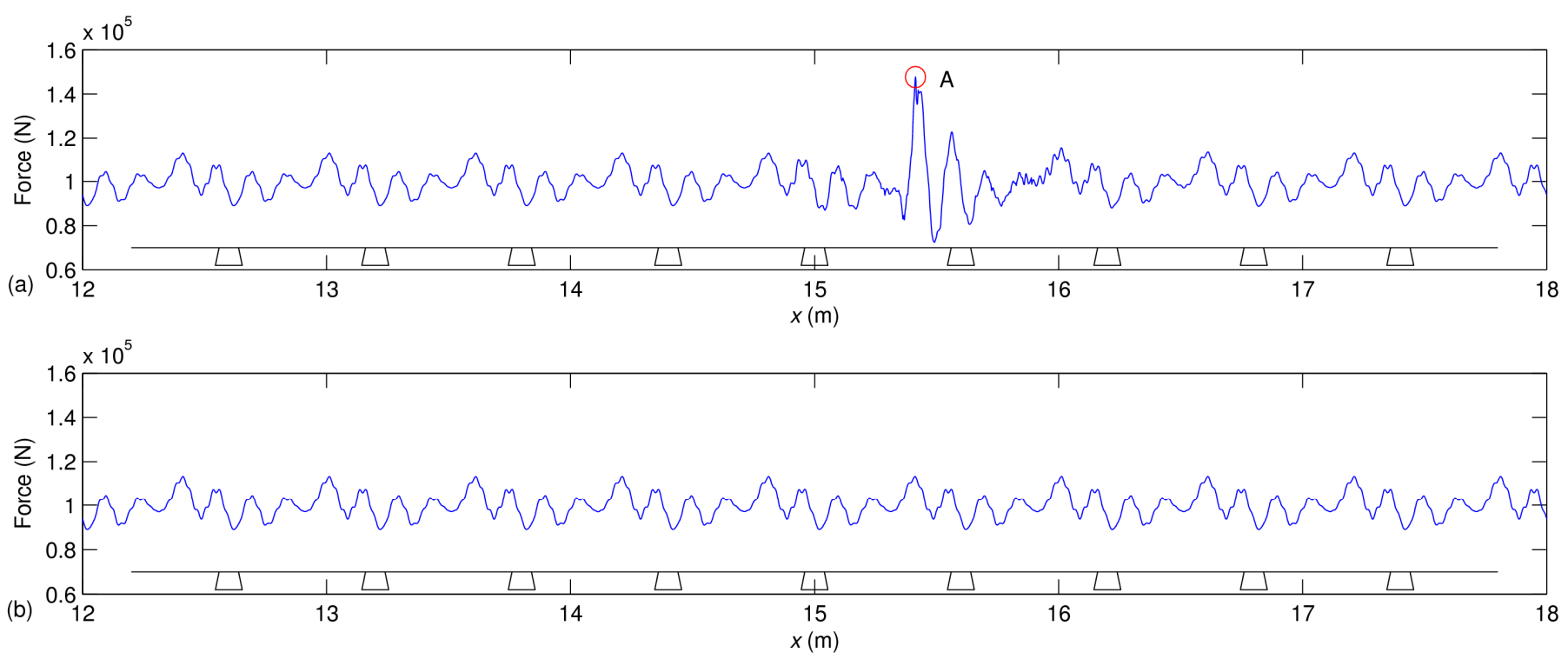

Fig. 8. Contact force: (a) due to wheel moving over a rail weld centred $40 \mathrm{~cm}$ after the sleeper, (b) due to wheel moving over a rail with discrete 
The force increase shown in Fig. 9 is due to the weld, but the existence of discrete supports provokes that force increase to change for the different values of $d$. The shape of Fig. 9 is much smoother than that of Fig 7. In Fig. 9 it can be noticed that, for this type of track, the maximum values of the force caused by travel over the weld would appear whenever the weld is over a sleeper, and they would be lower whenever the weld is at midspan.

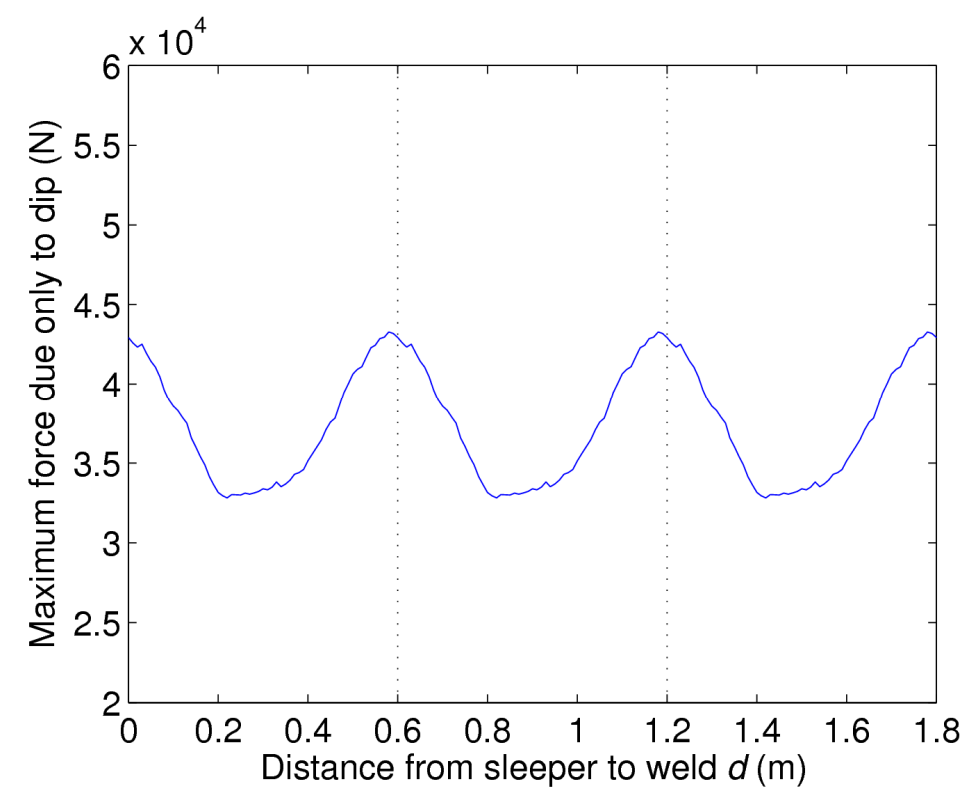

Fig. 9. Increase in maximum contact force due to the weld for different positions.

In the results that follow the interaction forces represented consider jointly the effects of the weld and of the sleepers.

Figs. 10 and 12 to 14 show the maximum value of the contact force during travel over the weld for different wheelset speeds and for different amplitudes of the dip and position of the centre of the weld. To carry out a quantitative study, it has seemed better to keep constant the defect shape, which corresponds to the real measurement depicted in Fig. 6, and to linearly scale it. The resulting welds, therefore, have not been obtained experimentally, but their dimensions fit within the range of a real weld.

The maximum force values of these Figs. 10 and 12 to 14 have been obtained from the detailed study of contact forces and the displacements of wheel and rail during travel over the weld, as shown in Fig. 11. This Fig. 11 corresponds to a speed of $80 \mathrm{~km} / \mathrm{h}$, circled in Fig. 10. The upper portion of Fig. 11 shows changes in the force over distance, while the lower portion represents the amplitude of wheel and rail displacements at the contact point.

Fig. 10 represents the maximum value of the force when the centre of the weld dip is in a section of the span located $15 \mathrm{~cm}$ after a sleeper, for cases in which the amplitude of the dip is that shown in Fig. 6 (factor 1), when amplitude is $50 \%$ greater (factor 1.5) and when magnitude is double that of the figure (factor 2).

The values of the maximum forces increase as speed increases up to the maximum value of $80 \mathrm{~km} / \mathrm{h}$, and subsequently decrease up to a speed of $140 \mathrm{~km} / \mathrm{h}$, after which they rise again. To confirm the rise, the values of the forces have been represented up to speeds of $300 \mathrm{~km} / \mathrm{h}$, well above the realistic speed range of freight trains. It is for this reason that values for speeds above $200 \mathrm{~km} / \mathrm{h}$ have been shown as a shaded area. Depicting speeds of up to 300 $\mathrm{km} / \mathrm{h}$ to show the shape of the curve of maximum values of the contact forces that would be obtained when speed increases, demonstrates the coherence of these results with those obtained for high-speed trains published in [11]. 
Fig. 10 shows that the curves for the different amplitudes of the dip follow the same trend as operating speed changes. Logically, the greatest forces emerge the greater the amplitude of the dip, as may be observed in the figure.

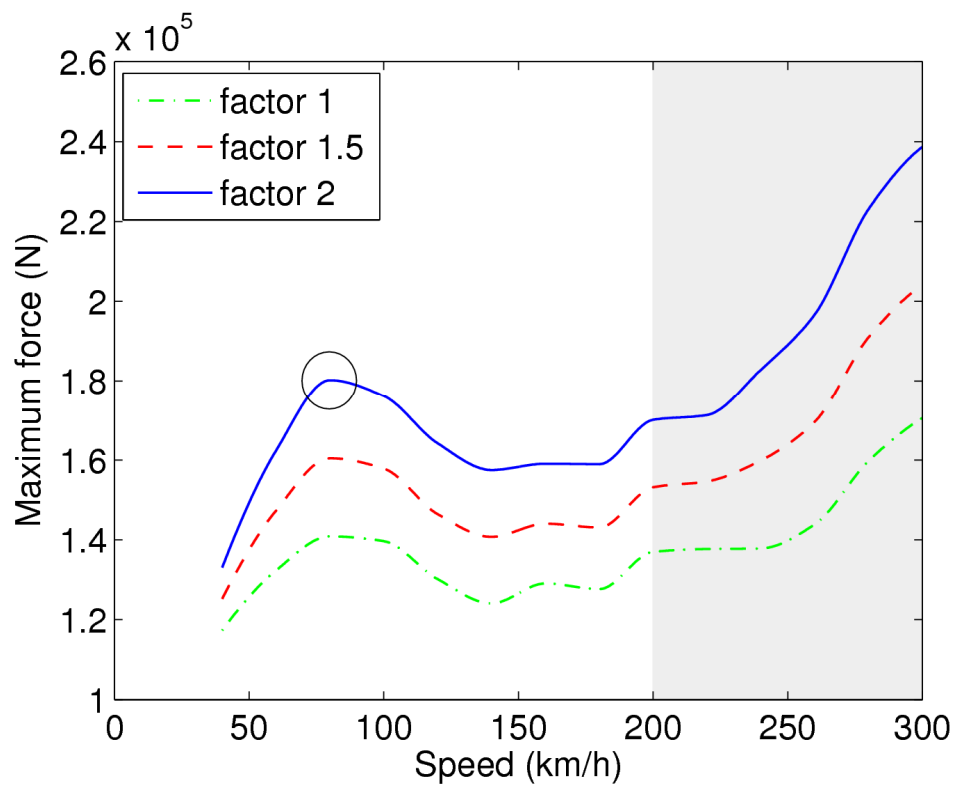

Fig. 10. Maximum forces during travel over a weld centred $15 \mathrm{~cm}$ after the sleeper.
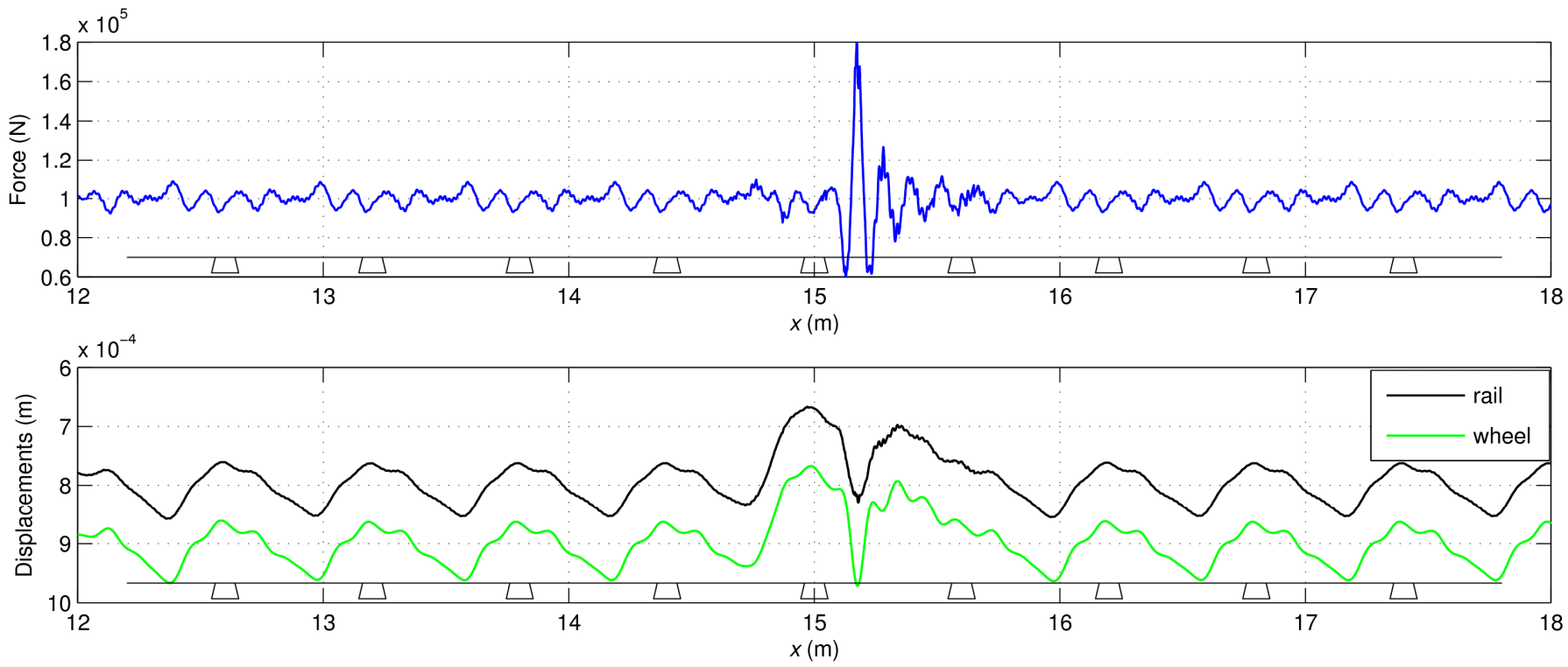

Fig. 11. Contact forces during travel at $80 \mathrm{~km} / \mathrm{h}$ over a weld centred $15 \mathrm{~cm}$ before the sleeper (above); wheel and rail displacements (below).

It can be noticed that for a weld double the amplitude of the original, the force attains values up to $180 \mathrm{kN}$, which represents an increase of $80 \%$. All the percentages included along the paper have been calculated referred to the contact static force. For the weld amplitude which is $150 \%$ of the original the maximum force reaches $160 \mathrm{kN}$, and for original weld amplitude $141 \mathrm{kN}$.

Fig. 12 displays the same results as Fig. 10, but in this case for a weld whose centre is located at midspan. In this case, the higher values of the force within the normal speed range arise at $100 \mathrm{~km} / \mathrm{h}$, with increases in the force of 76 $\mathrm{kN}, 58 \mathrm{kN}$ y $39 \mathrm{kN}$ with respect to the static force. 
Fig. 13, representing travel over a weld centred $15 \mathrm{~cm}$ before the sleeper, shows that the curves are much flatter within the normal freight train speed range. The maximum value emerges at $80 \mathrm{~km} / \mathrm{h}$, but remains very similar up to $200 \mathrm{~km} / \mathrm{h}$, particularly over welds the amplitude of which is $150 \%$ of the original. For the weld with an amplitude of $200 \%$ of the original, the differences arising from changes in speed are slightly greater. The respective maximum values for factors 2, 1.5 and 1 are $178 \mathrm{kN}, 157 \mathrm{kN}$ and $137 \mathrm{kN}$. It can be seen that, for different wheelset speeds, the results obtained when the weld is $15 \mathrm{~cm}$ before a sleeper and when it is $15 \mathrm{~cm}$ after the sleeper are different: for example, when the speed increases from $80 \mathrm{~km} / \mathrm{h}$ to $150 \mathrm{~km} / \mathrm{h}$, if the weld is centred $15 \mathrm{~cm}$ after the sleeper, the variation of the maximum contact forces is higher than in the case of the weld centred $15 \mathrm{~cm}$ before the sleeper.

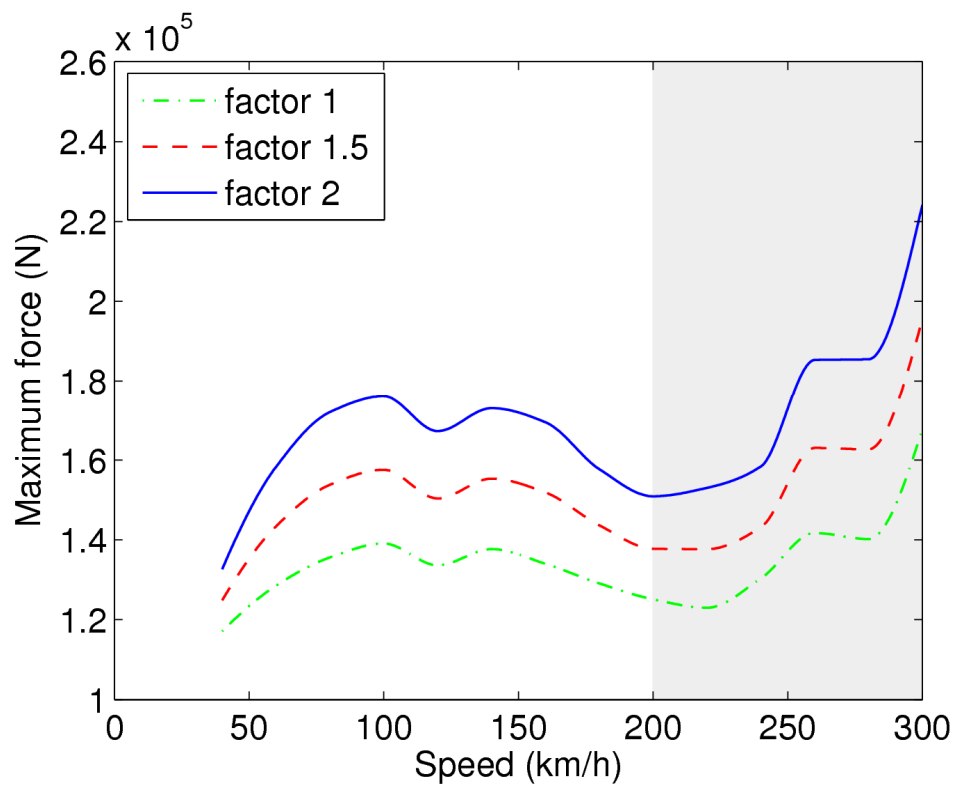

Fig. 12. Maximum values of the force during travel over a weld centred at midspan.

Fig. 14 shows the results of maximum forces when the weld is over the sleeper. Although in practice welds are never applied to sections over a sleeper, as it is impossible to insert the mould required for welding, when the rail neutral temperature is reset this weld may be located at any position on the span, even over the sleeper. If the weld is located in this section, it may be observed that the forces attained are greater than for a weld on other sections of the span. For a factor $2 \mathrm{dip}$ and a speed of $80 \mathrm{~km} / \mathrm{h}$, the force may be as much as $188 \mathrm{kN}$, which represents an increase of $88 \%$ with respect to the static load. When the amplitude of the dip is $150 \%$ of the original the force is $166 \mathrm{kN}$, and when the dip is the original this is $144 \mathrm{kN}$.

All the previous results have been summarised in Table 2 .

Table 2. Maximum forces as a function of the amplitude and position of the weld defect.

\begin{tabular}{cccc}
\hline \hline & Factor 1 & Factor 1.5 & Factor 2 \\
\hline $15 \mathrm{~cm}$ after the sleeper & $141 \mathrm{kN}$ & $160 \mathrm{kN}$ & $180 \mathrm{kN}$ \\
Midspan & $139 \mathrm{kN}$ & $158 \mathrm{kN}$ & $176 \mathrm{kN}$ \\
$15 \mathrm{~cm}$ before the sleeper & $137 \mathrm{kN}$ & $157 \mathrm{kN}$ & $178 \mathrm{kN}$ \\
Above the sleeper & $144 \mathrm{kN}$ & $166 \mathrm{kN}$ & $188 \mathrm{kN}$ \\
\hline \hline
\end{tabular}




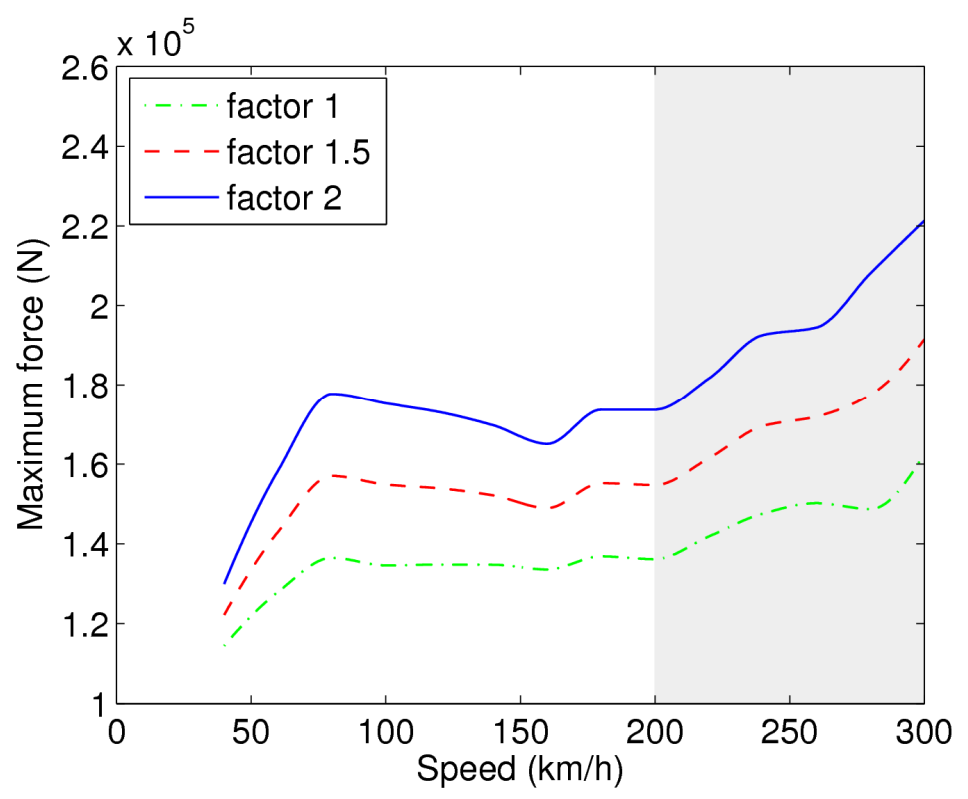

Fig. 13. Maximum values of the force during travel over a weld centred $15 \mathrm{~cm}$ before the sleeper.

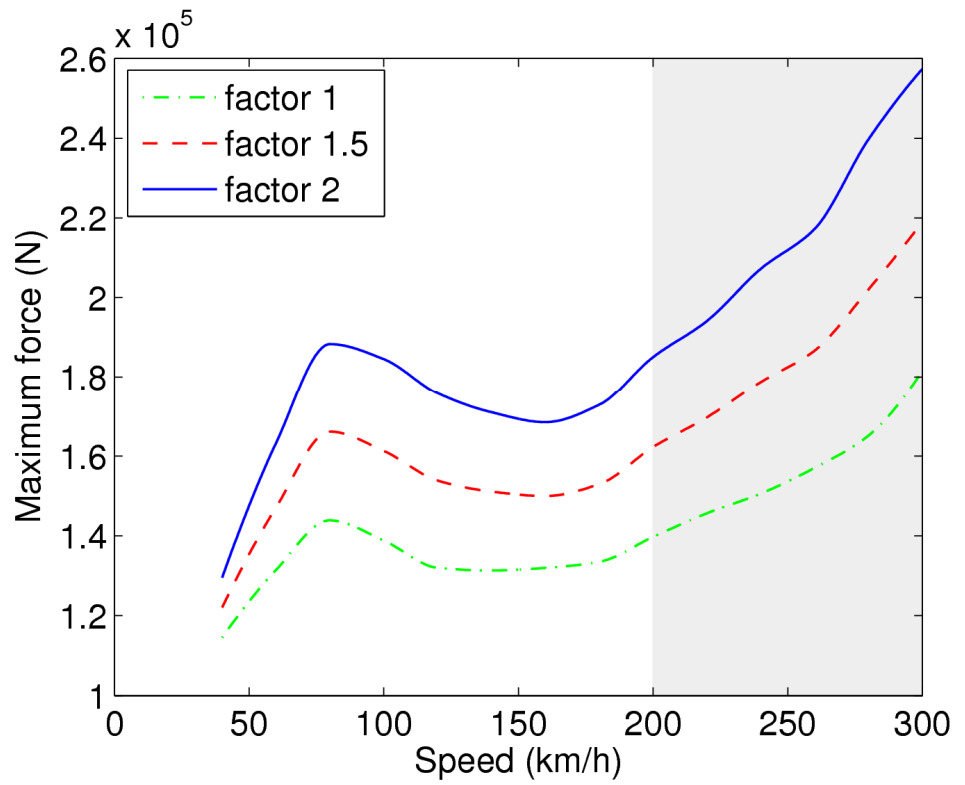

Fig. 14. Maximum values of the force during travel over a weld centred over the sleeper.

Some simulations have also been carried out changing the dip length. As expected, it has been obtained that the longer the dip is, the lower the maximum force becomes, and vice versa.

The results presented in this section have shown how maximum wheel-rail contact forces vary when a wheel moves over a rail weld. These maximum forces have a shape which has been studied as a result of changes in vehicle speed, while the amplitude and shape of the weld was kept constant. The maximum forces shape, as other authors have already noticed for wheel-rail excitations [14], increases with speed up to a certain limit above which the forces start to decrease. Finally, after a certain speed value, the curve recovers the increasing tendency with speed. It has been observed that this curve, and the specific speed for which the maximum forces start to decrease, depend on the distance from the rail weld to the nearest sleeper. As an example, while for a weld centred above the sleeper this peak value appears at $80 \mathrm{~km} / \mathrm{h}$, if the weld is located $30 \mathrm{~cm}$ after the sleeper that peak value appears at $100 \mathrm{~km} / \mathrm{h}$. Moreover, it has been observed that in the valley of the maximum force shape the maximum forces decrease as much 
as $25 \mathrm{kN}$.

As it has also been shown, if the maximum forces curves would have been represented only up to speeds of $200 \mathrm{~km} / \mathrm{h}$, in some cases we would have mistakenly concluded that beyond certain speed the maximum force against speed is always decreasing.

On the other hand, although initially the influence of the position of the rail weld on the maximum forces could have been considered negligible, it has been obtained that changes in the weld position can provoke variations in the maximum forces of up to $22 \%$ of the static load.

It has also been noticed during the calculations that the maximum contact force does not always appear at the same distance from the rail weld. That distance changes with speed. As an example, for a weld centred over the sleeper, increasing the speed from $160 \mathrm{~km} / \mathrm{h}$ to $200 \mathrm{~km} / \mathrm{h}$ moves the position of the peak force from $2 \mathrm{~cm}$ after the weld centre to $8 \mathrm{~cm}$. However these changes in distance are not monotonous.

\section{INFLUENCE OF AXLE LOAD AND WHEELSET UNSPRUNG MASS}

This section shows how contact forces vary in accordance with axle load and wheelset unsprung mass, for loaded and zero-load cars. Consideration has also been given to the possibility of lowering the unsprung mass, a current feature of some passenger trains. The aim of this section is to quantify the effect which increasing the load of freight cars would have on contact forces during travel over welds. In this case the dip geometry used is the one shown in Fig. 6.

Fig. 15 shows the maximum values of contact forces. As in the previous figures, the trend in this curve shows an increase up to a certain speed, almost $80 \mathrm{~km} / \mathrm{h}$ in this case, followed by a decrease up to a speed of around $140 \mathrm{~km} / \mathrm{h}$, whereupon a monotonous increase is observed. This format is maintained on all curves.

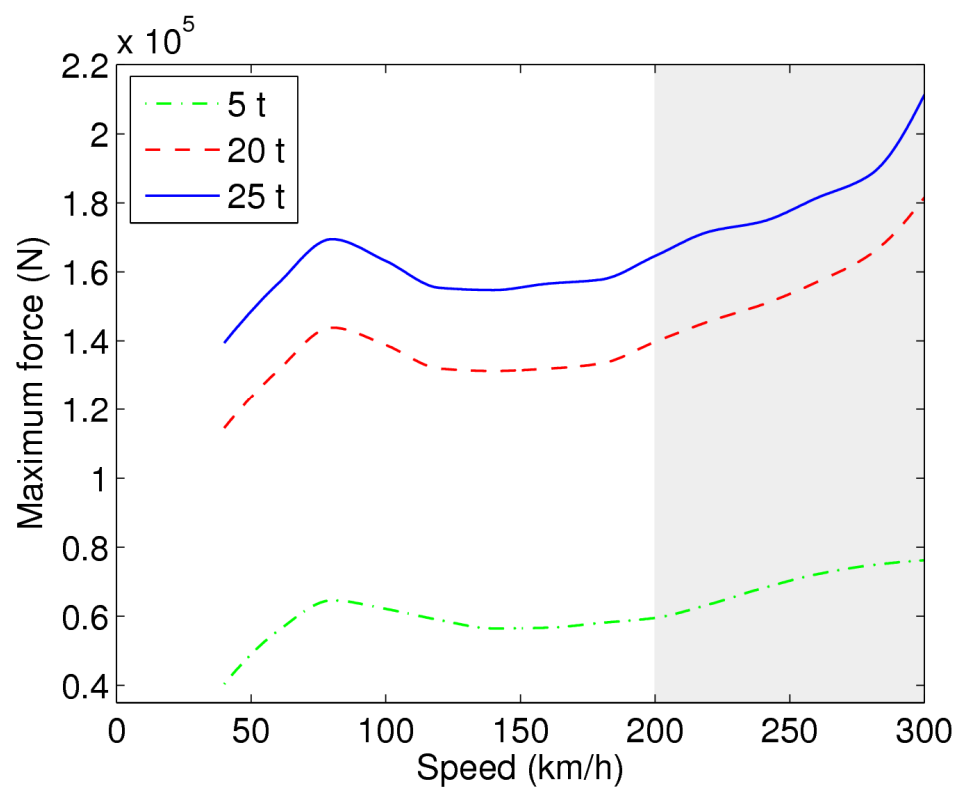

Fig. 15. Maximum values of the forces during travel of a $1200 \mathrm{~kg}$ wheelset over a weld for: an unloaded car (5 ton axle load); normal loaded car (20 ton axle load); heavily loaded car (25 ton axle load).

These figures represent the response for a weld centred on the sleeper since, at least for the types of track studied in this paper, the greatest forces in fact emerge when the weld is centred in this way. 
Fig. 15 shows the maximum force at different speeds when the $1200 \mathrm{~kg}$ wheelset moves over the weld shown in Fig. 6 (with its original amplitude). In Fig. 15 the following cases are included: the car is unloaded (5 ton axle load); the car is loaded (20 ton axle load); the car is heavily loaded ( 25 ton axle load). It can be seen that in the case of the unloaded car the resulting forces are very low. In this case the greatest contact forces arise when the wheelset moves over the dip at around $80 \mathrm{~km} / \mathrm{h}$, reaching $65 \mathrm{kN}$. This amounts to an increase in the contact force during travel over the weld of $40 \mathrm{kN}$, which is $160 \%$ increase with respect to static load. At speeds within the normal operating range of freight trains, following travel over the weld the contact receives a considerable discharge, which it has been ascertained could lead to a loss of contact at operating speeds in excess of $200 \mathrm{~km} / \mathrm{h}$. For a dip with an amplitude of 1.5 times the original, loss of contact occurs at speeds below $140 \mathrm{~km} / \mathrm{h}$, and hence within the normal operating speed range.

In the case of the 20 ton axle load car, the shape of the force is the same as in the previous case, although its maximum value is greater and can reach $144 \mathrm{kN}$ at $80 \mathrm{~km} / \mathrm{h}$, a $44 \%$ increase with respect to static load. This result has also been plotted in Fig.14, in the curve corresponding to a scale factor equal to 1, and is repeated here in order to facilitate the comparison of the results.

As seen in Fig. 15, in the case of a heavily loaded car (25 ton axle load), contact forces are, as expected, much higher than in the other two cases. Maximum force can reach $170 \mathrm{kN}$, representing a dynamic force that is $36 \%$ of the static force.

Fig. 16 compares contact forces for a heavily loaded car (25 ton axle load), using a normal $1200 \mathrm{~kg}$ wheelset and using a lighter $900 \mathrm{~kg}$ wheelset. It may be observed that there are no major differences between the maximum contact forces of the $1200 \mathrm{~kg}$ wheelset and the $900 \mathrm{~kg}$ wheelset in this case. The greatest differences between the original wheelset and the lighter wheelset emerge at a speed of $100 \mathrm{~km} / \mathrm{h}$, less than $3 \%$ in this case.

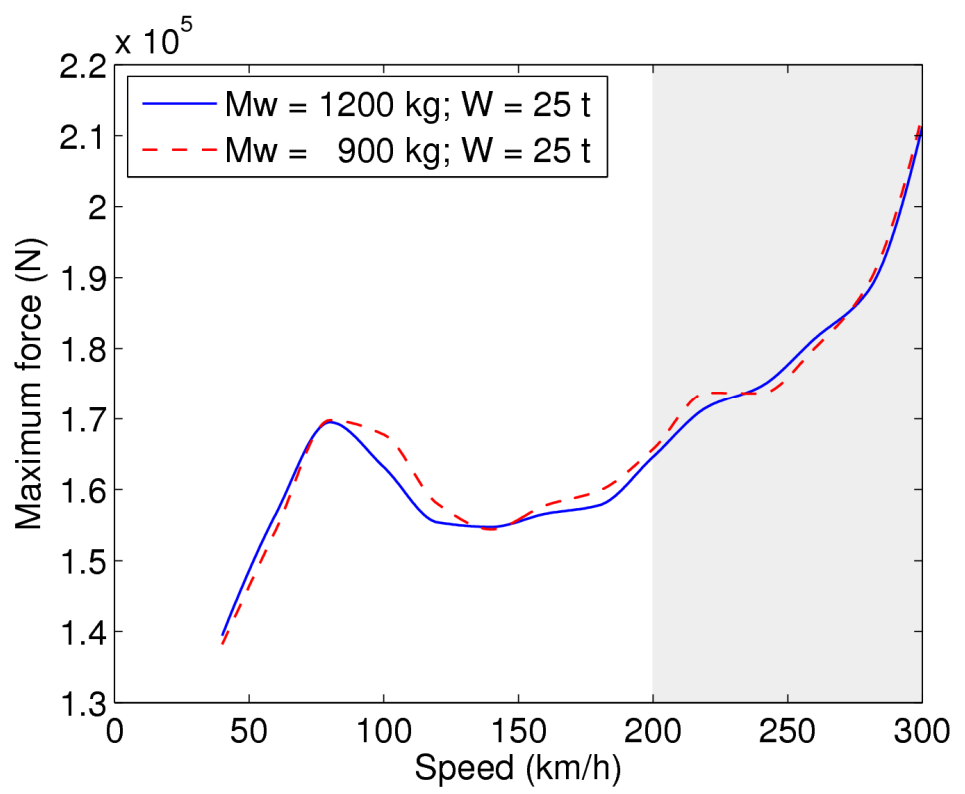

Fig. 16. Maximum values of the force during travel over a weld centred over the sleeper, with a heavily loaded car (25 ton axle load) and with: a normal $1200 \mathrm{~kg}$ wheelset and a lighter $900 \mathrm{~kg}$ wheelset.

In this section the effects of increasing the axle load on the maximum forces produced over a weld have been quantified. While this axle load increase, obviously, implies an increase in wheel-rail contact forces, it has been 
checked that the quotient between maximum force and axle load decreases, for all the train speeds analysed.

It has also been noticed that reducing the wheelset unsprung mass from $1200 \mathrm{~kg}$ to $900 \mathrm{~kg}$ has a low influence in the maximum contact forces.

In general, it has been observed that a moderate increase in train speed and in axle load does not imply a high increase in maximum contact forces when the wheel moves over the weld. This scarce increase of the contact forces, according to Archard's formula (Eq. (3)), commonly used to quantify wear in wheel-rail interaction, would also imply a scarce amount of wear in the contact between wheel and rail.

$\Delta V=\frac{k N s}{H}$

In Eq. (3), $\Delta V$ is the increase of worn material volume, $k$ is a wear constant, $N$ is the normal contact force, $s$ is the slip distance and $H$ is the penetration hardness of the softer material in the pair.

Track stiffness and damping parameters may vary largely from one track to another, and consequently responses to the welding defect may be very different from a stiff track to a very elastic track. However, for moderate changes in these parameters, the variation in the maximum contact forces should be lower than those obtained in the cases studied in this paper.

\section{CONCLUSIONS}

The paper examines the wheel/rail contact forces arising when a rail vehicle moves over weld dips. To this end a spatial domain model was used, obtained from the fitting of track receptances in the frequency domain, through joint utilisation of a rational fraction polynomial method and a multiobjective genetic algorithm optimisation method. This secures an extremely precise spatial model, albeit with very few degrees of freedom, and hence a very short calculation time. This enabled more than 1600 simulations to be carried out within a reasonable period of time for vehicles moving over a weld, for the different cases studied in the paper.

From the results obtained it may be concluded that, for the type and shape of the weld considered and the track deployed, increasing the speed of a freight train would only entail a moderate increase in the maximum contact forces compared to the present ones, at lower speeds.

Logically, moreover, increasing the axle loads leads to an increase in the maximum force arising during wheel/rail contact as the vehicle moves over the welding dip. It may also be observed in the case examined that reducing the unsprung mass would have moderate effects on the forces involved. The effect of the unsprung mass is even smaller with a large load on the wheelset.

Given the importance of increasing freight train speeds and axle loads to raise freight transport productivity, the results of this work may be of interest to evaluate the effects of these two variables in contact forces. Specifically, this article demonstrates that, for the type of track considered, if the speed of freight trains were to be increased from 120 $\mathrm{km} / \mathrm{h}$ to $160 \mathrm{~km} / \mathrm{h}$, with a simultaneous increase in axle load from 20 to 25 tonnes, for the weld dip considered, the maximum wheel/rail contact forces would increase by less than $20 \%$. 


\section{ACKNOWLEDGEMENTS}

The authors wish to thank the Spanish Research Ministry MICINN/Economy and Competitiveness Ministry MINECO for their funding through contract TRA2010-18386, including funding by the FEDER-ERDF European Regional Development Fund, and also the Basque Government for financial assistance through IT-453-10 and IT-691-13 as well as for Research Grant BFI08.172. They also extend their gratitude to the Basque Railway Infrastructure Manager ETS/RFV and Metro Bilbao for their assistance and valuable suggestions. The financial assistance received from UPV/EHU through the training and research unit UFI11/29 is likewise gratefully acknowledged.

\section{REFERENCES}

[1] J.C.O. Nielsen. High-frequency vertical wheel-rail contact forces-Validation of a prediction model by field testing, Wear. 265 (2008) 1465-1471.

[2] M.J.M.M. Steenbergen, C. Esveld. Rail weld geometry and assessment concepts, Journal of Rail and Rapid Transit. 220 (2006) 257-271.

[3] M.J.M.M. Steenbergen, C. Esveld. Relation between the geometry of rail welds and the dynamic wheel - rail response: numerical simulations for measured welds, Journal of Rail and Rapid Transit. 220 (2006) 409.

[4] M.J.M.M. Steenbergen. Quantification of dynamic wheel-rail contact forces at short rail irregularities and application to measured rail welds, J.Sound Vibrat. 312 (2008) 606-629.

[5] T.X. Wu, D.J. Thompson. Theoretical investigation of wheel/rail non-linear interaction due to roughness excitation, Veh.Syst.Dyn. 34 (2000) 261-282.

[6] T.X. Wu, D.J. Thompson. On the parametric excitation of the wheel/track system, J.Sound Vibrat. 278 (2004) 725-747.

[7] T. Mazilu, M. Dumitriu, C. Tudorache, M. Sebeşan. Using the Green's functions method to study wheelset/ballasted track vertical interaction, Math.Comput.Model. 54 (2011) 261-279.

[8] M. Molodova, Z Li, R. Dollevoet. Axle box acceleration: Measurement and simulation for detection of short track defects, Wear. 271 (2011) 349-356.

[9] P.A. Meehan, W.J.T. Daniel, T. Campey. Prediction of the growth of wear-type rail corrugation, Wear. 258 (2005) 1001-1013.

[10] Z. Wen, G. Xiao, X. Xiao, X. Jin, M. Zhu. Dynamic vehicle-track interaction and plastic deformation of rail at rail welds, Eng.Failure Anal. 16 (2009) 1221-1237.

[11] G. Xiao, X. Xiao, J. Guo, Z. Wen, X. Jin. Track dynamic behavior at rail welds at high speed, Acta Mechanica Sinica. 26 (2010) 449-465.

[12] W. Li, G. Xiao, Z. Wen, X. Xiao, X. Jin. Plastic deformation of curved rail at rail weld caused by train-track dynamic interaction, Wear. 271 (2011) 311-318.

[13] L. Baeza, H. Ouyang. A railway track dynamics model based on modal substructuring and a cyclic boundary condition, J.Sound Vibrat. 330 (2011) 75-86.

[14] A. Pieringer, W. Kropp, A fast-time-domain model for wheel/rail interaction demonstrated for the case of impact forces caused by wheel flats. Proc. of Acoustics '08, Paris, France, June 29-July 4, 2008.

[15] P.T. Torstensson, J.C.O. Nielsen, L. Baeza. Dynamic train-track interaction at high vehicle speeds-Modelling of wheelset dynamics and wheel rotation, J.Sound Vibrat. 330 (2011) 5309-5321.

[16] Z. Wen, G. Xiao, X. Xiao, X. Jin, M. Zhu. Dynamic vehicle-track interaction and plastic deformation of rail at rail welds, Eng.Failure Anal. 16 (2009) 1221-1237. 
[17] N. Correa, E.G. Vadillo, J. Santamaria, J Gómez. A rational fraction polynomials model to study vertical dynamic wheel-rail interaction, J.Sound Vibrat. 331 (2012) 1844-1858.

[18] J. Gómez, E.G. Vadillo, J. Santamaría. A comprehensive track model for the improvement of corrugation models, J.Sound Vibrat. 293 (2006) 522-534.

[19] M.H. Richardson, D. L. Formenti, Parameter estimation from frequency response measurements using rational fraction polynomials. (1982). 